\title{
Launching the Counterattack: Interdisciplinary Deployment of Native-Plant Functional Traits for Repair of Rangelands Dominated by Invasive Annual
} Grasses

\section{By Thomas A. Jones, Thomas A. Monaco, and Jeremy J. James}

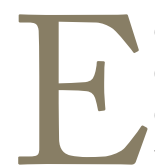

cologists worldwide recognize that the novel ecosystems of the future will display radically different structure and function from ecosystems that have dominated the study of ecology until the present. ${ }^{1}$ Human-modified systems are rapidly becoming more typical than exceptional, and models and management approaches that have been long regarded as orthodox and reliable seem to no longer apply.

Because of both abiotic and biotic obstacles, rangelands dominated by invasive plants are among the most difficult lands to repair. Invasive plants may be either the cause or effect of population declines of desirable native species. This uncertainty stems from observations that invasive plants can modify ecosystems in ways that favor themselves at the expense of native species. ${ }^{2}$ When an ecological threshold is crossed, a functional perennial-dominated ecosystem may be superseded by a dysfunctional annual-dominated ecosystem. This new state requires rigorous management inputs to repair ecological processes and to avert continuing dominance by invasive species. We have yet to learn how to reliably transition this problematic, modified ecosystem to a more stable and productive state.

Here, we make the case for designed, native plant materials using a conceptual framework that is anchored by functional traits that may overcome specific obstacles associated with annual-grass invasion. Such a functional-trait approach is based upon the interplay of three scientific disciplines: ecology, physiology, and genetics. We contend that three-pronged interdisciplinary tactics are as essential to developing functional postmodern ecosystems as the infantry, cavalry, and artillery were to effective military combat in the 19th century. Just as a three-legged stool cannot stand on one or two legs, we believe that attempts to rectify invasive-species dominance based on only one or two of the said disciplines will ultimately fail. We further believe that plant populations that display appropriate levels and diversity for functional traits may interact to form viable communities that are more stable and resilient in the face of invasive plants. Ecological niches are increasingly likely to be occupied by desirable perennial species over time, rather than by the invasive plants that characterize ecosystem dysfunction.

We argue herein that native-plant performance trumps indigenous genotypes in the case of modified ecosystems. Insistence on the exclusive use of indigenous genotypes in the presence of invasive competitors places an elevated emphasis on taxonomy and genetics while restraining the ecological processes and physiological relationships that can rejuvenate these ecosystems. Nevertheless, we also recognize that indigenous genotypes may contribute to the solution when combined with applicable ecological and physiological principles, as we have argued previously. ${ }^{3}$

\section{Altered Ecological Processes}

To develop native plant materials capable of reversing the ecological impacts of annual-grass invasion, it is important to categorize the primary obstacles introduced by invasion that challenge underlying ecological processes (Table 1). Instead of listing the manifold ecological processes that are 


\begin{tabular}{|c|c|c|}
\hline Obstacles & Ecological Process & Functional Trait(s) \\
\hline \multirow[t]{3}{*}{$\begin{array}{l}\text { Priority } \\
\text { effects }\end{array}$} & Dispersal & $\begin{array}{l}\text { Seed production } \\
\text { and size }\end{array}$ \\
\hline & Germination & $\begin{array}{l}\text { Seed quality and } \\
\text { dormancy }\end{array}$ \\
\hline & Emergence & $\begin{array}{l}\text { Relative growth rate } \\
\text { (root and shoot) }\end{array}$ \\
\hline \multirow[t]{3}{*}{ Interference } & Rate of development & $\begin{array}{l}\text { SLA and cold- } \\
\text { temperature growth } \\
\text { tolerance }\end{array}$ \\
\hline & Nitrogen capture & $\begin{array}{l}\text { Leaf nitrogen } \\
\text { productivity and } \\
\text { root length }\end{array}$ \\
\hline & $\begin{array}{l}\text { Root foraging and } \\
\text { exploitation }\end{array}$ & $\begin{array}{l}\text { Acquisition of } \\
\text { nutrient pulses } \\
\text { (in space and time) }\end{array}$ \\
\hline \multirow{3}{*}{$\begin{array}{l}\text { Positive } \\
\text { feedback } \\
\text { types }\end{array}$} & $\begin{array}{l}\text { Soil nutrient } \\
\text { dynamics }\end{array}$ & $\begin{array}{l}\text { Leaf C:N ratio and } \\
\text { tissue longevity }\end{array}$ \\
\hline & $\begin{array}{l}\text { Fire frequency and } \\
\text { intensity }\end{array}$ & $\begin{array}{l}\text { Litter production } \\
\text { and fire tolerance }\end{array}$ \\
\hline & $\begin{array}{l}\text { Soil structure, } \\
\text { surface microtopog- } \\
\text { raphy, and hydrology }\end{array}$ & $\begin{array}{l}\text { Root strength } \\
\text { and desiccation } \\
\text { tolerance }\end{array}$ \\
\hline
\end{tabular}

SLA indicates specific leaf area; C:N, carbon:nitrogen ratio.

altered by annual-grass invasion, we categorize ecological processes according to three of the most contemporarily referenced obstacles in the invasion literature: priority effects, interference, and positive feedbacks. In doing this, our goal is to make direct linkages between altered ecological processes and specific functional traits, that, when expressed by native species, facilitate the repair of ecological processes that drive functional ecosystems.

\section{Priority Effects}

Annual-grass invasion is a process with distinct stages (Vasquez et al., this issue). Disturbance facilitates the spread and dominance of invasive annual grasses and creates unoccupied physical spaces. Through the processes of dispersal, germination, and emergence, annual grasses can rapidly colonize unoccupied space during the early phases of community assembly. In essence, high seed production, effective seed-dispersal mechanisms, and rapid germination and emergence enable invasive annual grasses to gain "priority effects" in community assembly. ${ }^{4}$ Priority effects are important because those species that arrive first occupy space and control resource dynamics. In turn, these species are most likely to become ecosystem drivers and to determine successive trajectories. Removing undesirable priority effects prior to restoration efforts is thus a critical component of integrated management.

It is reasonable to hypothesize that the processes used by invasive annual grasses to colonize and establish following disturbance would also assist native, perennial plant materials during restoration. Therefore, functional traits directly linked to dispersal ability, high germination rate, and rapid emergence should be emphasized when selecting native plant materials to overcome the priority effects associated with annual-grass dominance.

\section{Interference}

It is widely recognized that invasive annual grasses strongly interfere with native species, especially during the early phases of community assembly when most restoration efforts are undertaken. The obstacle created by interference stems from some of the most-studied processes in invasion ecology: rate of plant development, nitrogen capture, and root foraging and exploitation. These processes disrupt the growth of native species primarily through depleting resource availability during a seasonal period when seedlings of native species are most vulnerable. Because native species are typically seeded in late fall with emergence occurring in the following spring, the interference effects of invasive annual grasses directly coincide with emergence of native species. Not only are rapid growth and development in late winter and early spring a further extension of priority effects by annuals, they also provide direct advantages for accessing soil-resource pools when resources are typically most abundant. The superior ability of invasive annual grasses to capture mineralized forms of nitrogen during this period has been linked to high leaf-nitrogen productivity and rapid deployment of root length (Drenovsky and James, this issue). These key functional traits enable the invasive grasses to pre-empt soil water and nitrogen resource pools. Rapid shoot and root development and initial control over soil-resource pools may also cause substantial interference with native species that germinate and emerge considerably later. Initial control of soil resources and rapid deployment of root biomass also have been linked to the high capacity of invasive annual grasses to exploit resource pulses associated with spring precipitation events. Thus, interference from invasive annual grasses on native-species growth and development can extend into the summer, when drought and high ambient temperatures emerge as critical abiotic stresses.

Recognizing the key processes responsible for annualgrass interference is a necessary precursor for both on-theground management and development of effective native plant materials. If significant measures are not taken to reduce the anticipated priority and interference effects, restoration 
strategies that include seeding native species are destined to fail. In contrast, if control measures substantially reduce these effects prior to seeding, the performance of native species will rely more on key functional traits of the seeded species and how they are expressed during the early phases of community assembly. Here, we not only link obstacles to ecological processes, we also suggest that an integration of guiding management principles and native plant materials is essential for optimal levels of performance.

\section{Positive Feedback}

In the last decade, research on plant-soil feedback has greatly expanded our understanding of how invasive plants are capable of modifying soil and disturbance regimes to facilitate further invasion (Eviner et al., this issue). Certain types of positive feedback present large obstacles to restoration because they alter key ecosystem processes (Table 1). In this article, we focus on a few of the most commonly recognized ways in which annual-grass invasion generates positive feedbacks that subsequently alter ecological processes. As illustrated above, annual grasses accrue priority effects that greatly interfere with native-species success. Consequently, invasive annual grasses dominate the ecosystem and exert greater control on soil-nutrient dynamics than do remnant native species. These changes are a consequence of nutrient-uptake patterns described above (under Interference), as well as the quality and abundance of leaf litter produced by invasive annual grasses. This abundant litter is believed to reduce the soil's organic-matter quality and increase mineralization potential of soils. Ultimately, these changes are believed to favor continued dominance by invasive annual grasses because they produce abundant biomass that is rapidly mineralized (Drenovsky and James, this issue). Abundant litter also generates positive feedbacks involving wildfire. Frequent fires reinforce the dominance of invasive annual grasses, which are not impacted directly by fire because they complete their life cycles and replenish their seed banks prior to the onset of the fire season. Crown meristems of perennial bunchgrasses, on the other hand, are usually damaged by fire.

Finally, historical disturbances that lead to annual-grass dominance also alter soil structure, surface microtopography, and hydrology in ways that present considerable obstacles to native-species establishment and survival. Some of the most recognized examples include reduced biotic crusts, greater surface compaction, fewer safe sites for native-seed placement, and low levels of water infiltration into the soil. Although it is not possible to directly attribute the effects of annual-grass invasion to alteration of these three processes, evidence indicates that these processes are fundamentally different between invaded and intact native ecosystems. The continued dominance of invasive annual grasses may result from a combination of their high performance under these altered ecological conditions and the handicaps realized by native perennials under these same circumstances.
Collectively, positive feedbacks, regardless of whether they are initiated by annual grass invasion, reinforce annualgrass dominance and create tremendous obstacles to restoration efforts. Because key ecological processes have been altered, native species must be able to perform well under these conditions and/or potentially influence ecological processes in ways that build ecosystem resilience while minimizing positive feedbacks generated by annual plants. If such plant materials can be developed, they may serve as a biotic trigger to move an undesirable stage toward a more desirable state via a defined "restoration pathway." Even when pre-seeding treatments (e.g., herbicide applications) minimize the dominance held by invasive annual grasses, native species must still be able to establish and persist under challenging modified environments. Functional traits that may be critical to accomplishing this feat include low litter production to reduce fire frequency, high leaf carbon: nitrogen $(\mathrm{C}: \mathrm{N})$ ratio and concomitant high leaf longevity to regenerate soil-nutrient cycles, and exceptional root strength and desiccation tolerance to facilitate survival in compacted soils with poor water infiltration.

\section{Functional Traits to the Rescue}

Ecologists have spent the last several decades examining how species and functional-group diversity influence ecosystem properties such as productivity and invasion resistance. Central principles of restoration have been developed based on the assumption that seeding a diversity of species will confer greater invasion resistance than seeding less-diverse seed mixtures. However, plant physiology research over this same time period has demonstrated that a species' response to, as well as its impact on, its immediate environment is best predicted by its functional traits. ${ }^{6}$ Understanding how native and invasive plants differ in this respect can provide important insight into what types of plant materials are most appropriate for a given restoration scenario. This information can also be used to identify major gaps in commercially available plant material and to provide ecological targets for future plant materials.

Research in plant physiology has provided strong evidence for a trade-off between the ability of plants to capture resources and their ability to conserve resources. ${ }^{7}$ Not surprisingly, most invasive species tend to have rapid resource capture, yet poor resource conservation ( $r$-strategists), while most natives tend to have low resource capture, yet high resource conservation ( $K$-strategists). One way the trade-off between these two strategies can be explained is by considering how plants construct leaf and root tissues. Most invasive annuals construct thinner root and leaf tissues, while most native perennials construct thicker root and leaf tissues. This means that, for every gram of biomass synthesized via photosynthesis, invasive annuals can generate more leaf and root area than native perennials. This allows invasive annuals to capture significantly more resources and provides them with an initial competitive advantage 
during the seedling-establishment phase. Efforts to identify and select desirable plant materials with leaf- and rootconstruction strategies more similar to those of invasive species may improve our ability to restore invader-dominated ecosystems. For example, bottlebrush squirreltail (Elymus elymoides) and Sandberg bluegrass (Poa secunda) are shortlived perennial bunchgrasses with attributes similar to invasive annual grasses, such as early maturity and high reproductive output.

Another recent advance in understanding functional traits concerns how natives and invasives differ in their ability to tolerate low-nutrient soils. Comparative work has shown that invasives often display higher resource-use efficiency than natives. ${ }^{8}$ Taken together, efficient construction of leaf and root surface area and efficient use of resources may give invasives a distinct advantage in nutrient-poor soils during the seedling-establishment phase. With these functional traits, not only can invasive species rapidly preempt natives for most nutrients, they may also ultimately require fewer nutrients to maintain physiological processes such as photosynthesis. Little is known regarding nutrientuse efficiency characteristics of native plants or how these traits vary among native plant populations. Moreover, further advances in plant materials may identify or lead to the development of plant materials with nutrient-use characteristics comparable to our most serious invaders.

Most work on functional traits has focused on seedlings or established plants. However, ecological processes that occur during germination, described above as "priority effects," are instrumental in determining restoration outcomes. Early germination and emergence can increase the probability that a seedling survives seasonal drought and proves to be more competitive. ${ }^{9}$ Early germination and emergence of annual invasive grasses are considered to be major factors limiting establishment of native perennial grass seedlings. The difference in germination timing between invasive annual grasses and native perennial grasses is due to the lesser amount of hydrothermal time required to initiate germination by annual grasses. While early germination and emergence are two traits that are thought to contribute to the success of introduced grasses such as crested wheatgrass, there has been little experimental field assessment of how timing of germination and emergence differs among commonly seeded species or populations within species. Initial work in laboratory germinators has shown that the hydrothermal time requirement has a strong genetic component. ${ }^{10}$ Functional traits of germinating seedlings are underexplored when compared to traits associated with established seedlings and mature plants. Identifying plant materials with lower hydrothermal time requirements may be an important way to overcome the strong priority effects typically exhibited by invasive plants.

\section{Plant Material Solutions}

Consideration of functional traits for the design of restoration plans has been largely limited to the assignment of individual species to broadly defined functional groups. This brief overview, however, outlines how targeting multiple, key functional traits in seeding mixtures has the potential to improve the potential for restoring ecosystem structure and function to weed-infested systems. One of the central points that has emerged is the need to understand the degree to which these functional traits vary among commonly used plant materials and to identify where major gaps exist. A second point is that we have a suite of traits to consider, with different traits being important at different life stages. Because of this, ecologists and physiologists will need to collaborate with geneticists to not only identify and develop appropriate plant materials, but also to develop practical decision-support tools to assist practitioners in selecting appropriate plant materials for various restoration scenarios.

By relying on a single plant material per species in restoration seedings, restoration practitioners often miss the opportunity to enhance within-species functional diversity. As previously stated, probably the most functionally similar perennial native bunchgrasses relative to downy brome (Bromus tectorum) are the native bluegrasses (Poa spp.) and squirreltails (Elymus spp.). These are species "complexes" that possess high levels of functional diversity. By seeding combinations of Mountain Home and High Plains germplasms ( $P$. secunda), Opportunity germplasm ( $P$. nevadensis), and "Sherman" ( $P$. ampla), more niche space may be saturated than by using any of these plant materials alone. Likewise, seeding Rattlesnake or Fish Creek germplasms (E. elymoides subsp. elymoides), Toe Jam Creek germplasm (E. elymoides subsp. californicus), and Sand Hollow germplasm (E. multisetus) together would accomplish functional diversity for this complex. For both bluegrass and squirreltail, these plant materials encompass a broad phenological range extending from early to medium maturity dates in the order listed above. Thus, across time they may consume resources and occupy more niches that would otherwise harbor invasive species.

The native bluegrasses and squirreltails may spread across space by seed, even when initial stands are very sparse. Squirreltails are self-compatible and do not need to be pollinated by another individual to produce seed. Similarly, individual bluegrass plants may produce seed through an asexual "photo-copying" process called pseudogamous apomixis, again without the need of pollen from other individuals. These bluegrasses and squirreltail are bunchgrasses; inclusion of rhizomatous grasses in the seeding mix may facilitate additional capture of niches across space. Through rhizomatous spreading, western wheatgrass (Pascopyrum smithii) and thickspike wheatgrass (Elymus lanceolatus) can expand their niche occupation, especially into seeded-row interspaces. While western wheatgrass and thickspike wheatgrass may spread across space through their extensive rhizomes, they are self-incompatible and require pollen from other individuals to set seed. 

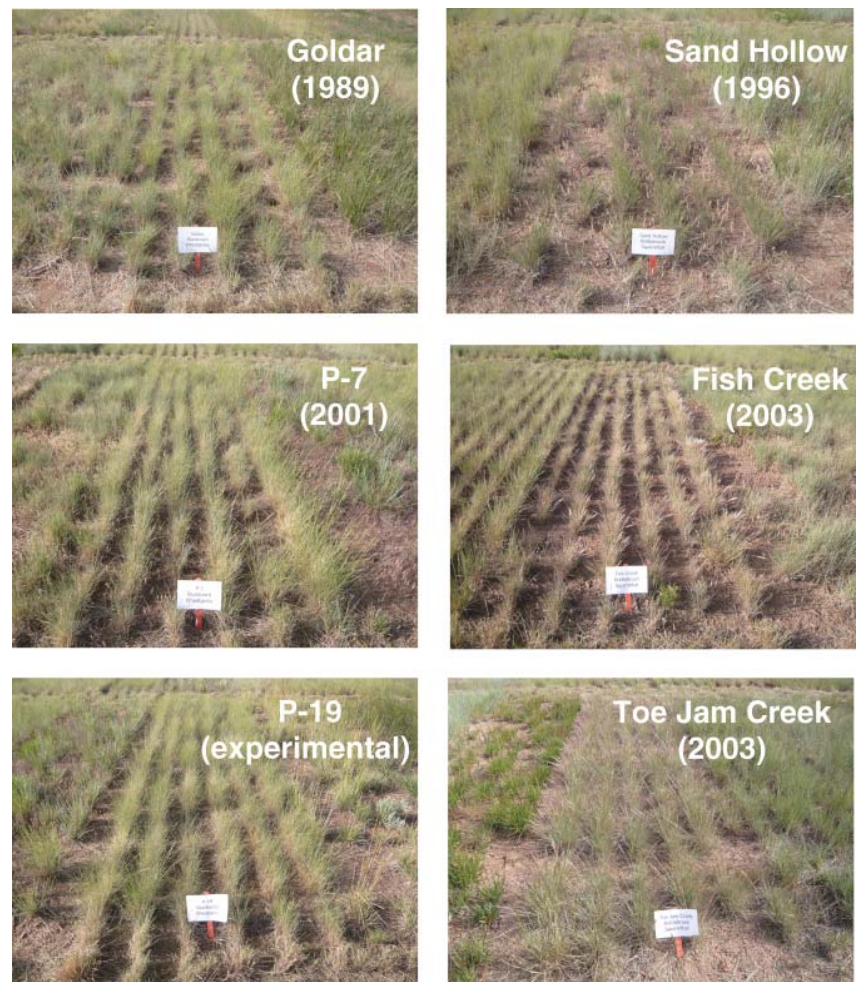

Figure 1. Plant material comparisons (2009) in a trial dormant-seeded in fall 2007 near Beaver, Utah. Bluebunch wheatgrass (left) and squirreltail (right) plant materials and dates of release demonstrate the improvements in performance accomplished in a long-term plant-material development program.

Instead of overemphasizing historical authenticity, implementation of a functional ecosystem fosters selfregenerating processes in the modified environments that increasingly occupy our planet. ${ }^{11}$ But how can plant materials be used to secure this future? In short, such plant materials may be developed by harnessing the power of "assisted evolution." 3 This approach aims to do the following: 1) restore ecosystem structure and function, 2) display adaptation to the modified environment, and 3) reflect general historical evolutionary patterns. Through close examination of specific functional traits, new plant materials may be deployed with heightened potential for repair of impaired ecosystems (Fig. 1). If restoration outcomes are to be successful, functional traits of such plant materials must be able to counter the primary biotic obstacles associated with annual-grass invasions.

\section{References}

1. Ноbbs, R. J., S. Arico, J. Aronson, J. S. Baron, P. Bridgewater, V. A. Cramer, P. R. Epstein, J. J. Ewel, C. A. Klink, A. E. Lugo, D. Norton, D. Ojima, D. M.
Richardson, E. W. Sanderson, F. Valladeres, M. Vilá, Regino Zamora, and M. Zobel. 2006. Novel ecosystems: theoretical and management aspects of the new ecological world order. Global Ecology and Biogeography 15:1-7.

2. Kulmatisiki, A., K. H. Beard, J. R. Stevens, and S. M. СоввоцD. 2008. Plant-soil feedbacks: a meta-analytical review. Ecology Letters 11:980-992.

3. Jones, T. A., and T. A. Monaco. 2009. A role for assisted evolution in designing native plant materials for domesticated landscapes. Frontiers in Ecology and the Environment 7:541547.

4. LuLow, M. E. 2006. Invasion by non-native annual grasses: the importance of species biomass, composition, and time among California native grasses of the Central Valley. Restoration Ecology 14:616-626.

5. Briske, D. D., B. T. Bestelmeyer, T. K. Stringham, and P. L. Shaver. 2008. Recommendations for development of resilience-based state-and-transition models. Rangeland Ecology and Management 61:359-367.

6. Díaz, S., and M. Cabido. 2001. Vive la différence: plant functional diversity matters to ecosystem processes. Trends in Ecology and Evolution 16:646-655.

7. Reich, P. B., I. J. Wright, J. Cavender-Bares, J. M. Craine, J. Olekssyn, M. Westoby, and M. B. Walters. 2003. The evolution of plant functional variation: traits, spectra, and strategies. International Journal of Plant Science 164(Suppl):S143-S164.

8. Funk, J. L., and P. M. Vitousek. 2007. Resource-use efficiency and plant invasion in low-resource systems. Nature 446:1079-1081.

9. Verdu, M., and A. Traveset. 2005. Early emergence enhances plant fitness: a phylogenetically controlled metaanalysis. Ecology 86:1385-1394.

10. Hardegree, S. P., T. A. Jones, F. B. Pierson, P. E. Clark, And G. N. Flerchinger. 2008. Dynamic variability in thermal-germination response of squirreltail (Elymus elymoides and Elymus multisetus). Environmental and Experimental Botany 62:120-128.

11. Clewell, A. 2000. Restoring for natural authenticity. Ecological Restoration 18:216-217.

Authors are Research Geneticist, USDA-Agricultural Research Service, Forage and Range Research Laboratory, Utah State University, Logan, UT 84322, USA, thomas.jones@ars.usda. gov (Jones); Research Ecologist, USDA-Agricultural Research Service, Forage and Range Research Laboratory, Utah State University, Logan, UT 84322, USA (Monaco); and Plant Physiologist, USDA-Agricultural Research Service, Range and Meadow Forage Management Research Unit, Eastern Oregon Agricultural Research Center, Burns, OR 97720, USA (James). Additional references are available at www.srmjournals.org. 